\title{
Science and Charity, Picasso's Realistic Masterpiece
}

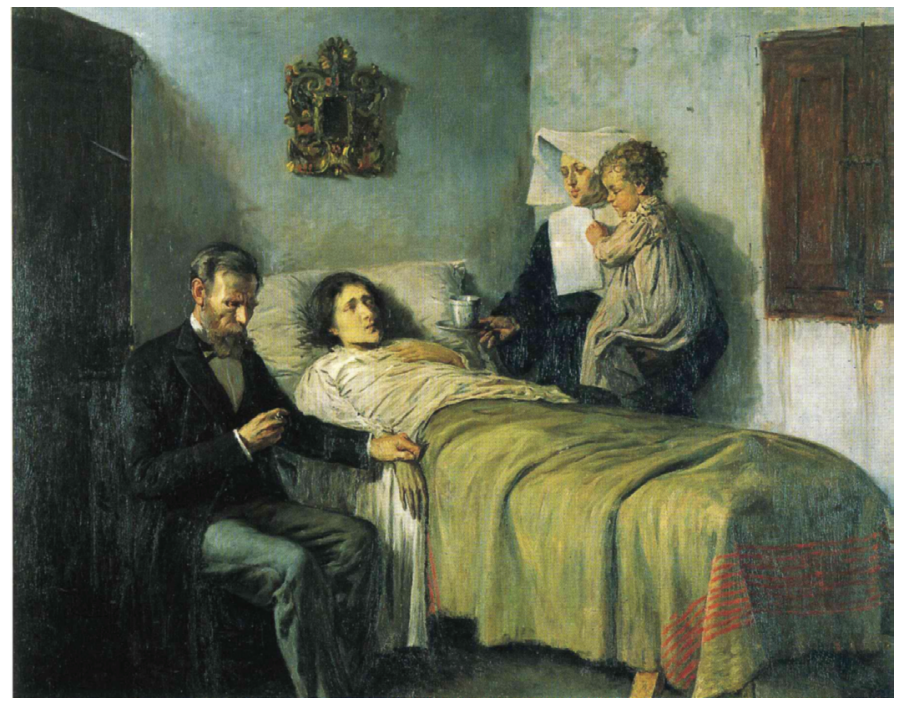

When most individuals think of Pablo Picasso, they think of Cubism, an art movement he helped create with artist Georges Braque. However, Picasso started his career as a realistic painter, beginning at a very young age since his father was an artist and instructor. One of Picasso's first major works was Science and Charity (1897), a very large canvas at $197 \times 249.5 \mathrm{~cm}(6.5 \times 8$ feet $)$. What's more amazing is that Science and Charity was painted when Picasso was the very young age of 15 and living in Barcelona. This painting also marks the height of Picasso's academic painting and his time at the San Fernando Academy in Madrid; soon he would turn his attention to more experimental ways of representing the world.
Science and Charity features a common compositional approach of the time: combining aspects of science and faith in a social realistic style. The painting's central figure of a sick woman is surrounded on either side by the figure of science on her right and that of charity on her left. Charity is represented through the nun's habit, which Picasso modeled off a borrowed piece of clothing he obtained through his uncle. Charity extends a drinking vessel to the sick woman, while holding a child in her other arm. In real life, the child was actually related to the sick woman in the bed; the woman and child were two beggars hired by Picasso as models for this painting. The role of Science is assumed by the gentlemen sitting in a chair, with one hand holding a small watch and the other taking the sick woman's pulse. The figure of the doctor held a special relationship to the artist; the model was Picasso's father, José Ruiz Blasco.

Corresponding author: Christian Conrad PhD Author affiliation: Museum of Texas Tech University, Lubbock, TX

Information: conradmerz@yahoo.com

Submitted: 5/11/2017

Conflicts of interest: none

\section{REFERENCE}

Museo Picasso. http://www.bcn.cat/museupicasso/en/collection/ mpb110-046.html

DOI: $10.12746 /$ swrccc.v5i20.405 